\title{
Faktor yang berhubungan dengan personal hygiene pada remaja putri SMP Negeri 4 Majene
}

\author{
Muzakkir ${ }^{1}$ Muh Fauzar Al-Hijrah ${ }^{2}$ Hermin Husaeni $^{2}$ Ika Muzdalia ${ }^{2}$ \\ 1) Stikes Nani Hasanuddin Makassar \\ ${ }^{2)}$ Prodi S1 Keperawatan Universitas Sulawesi Barat
}

\author{
Keywords : \\ Knowledge, Trust, and Personal \\ Hygiene
}

Kontak :

Muzakkir

Email :

Muzakkirnani@gmail.com

Stikes Nani Hasanuddin Makassar

DOI : https://doi.org/10.15294/

kemas.v14i3.1562

(C)2020J-Healt

ini adalah artikel dengan akses terbuka

dibawah licenci CC BY-NC-4.0

https://creativecommons.org/licenses/by-nc/4.0/

\begin{abstract}
Abstrak :
Personal hygiene adalah suatu tindakan untuk memelihara kebersihan dan kesehatan seseorang untuk kesejahteraan, baik fisik maupun psikisnya. Jika seseorang sakit, biasanya masalah kesehatan kurang diperhatikan. Hal ini terjadi karena mengganggap masalah kebersihan adalah masalah sepele, padahal jika hal tersebut kurang diperhatikan dapat mempengaruhi kesehatan secara umum. Penelitian ini bertujuan untuk mengetahui faktor yang berhubungan dengan personal hygiene pada remaja putri di SMP Neg 4 Majene. Penelitian ini menggunakan rancangan survei analitik dengan pendekatan cross sectional study. Penelitian ini dilaksanakan di SMP Neg 4 Majene Kabupaten Majene dengan jumlah total sampel 47 remaja putri. Pengambilan sampel dilakukan dengan metode total sampling. Hasil penelitian menunjukkan perilaku personal hygiene cukup sebesar 31 orang $(65.1 \%)$ dan kurang sebesar 16 orang (34.9\%). Hasil uji Chi-Square menunjukkan tidak ada hubungan antara tingkat pengetahuan remaja putri dengan personal hygiene dengan nilai Fisher Exact diperoleh nilai $p=1.00$ dan tidak ada hubungan antara tingkat kepercayaan remaja putri dengan personal hygiene dengan nilai continuity correction diperoleh nilai $p=0.533$. Kesimpulan dari penelitian ini adalah tidak ada hubungan antara faktor pengetahuan dan kepercayaan terhadap personal hygiene remaja putri SMP Neg 4 Majene.
\end{abstract}

\section{Abstract}

Personal hygiene is an action to maintain the cleanliness and health of a person for his welfare, both physical and psychological. If someone is sick, usually the health problem is less attention. This happens because it considers the problem of cleanliness is a trivial problem, even though if it is not paid attention to can affect general health. This study aims to determine the factors associated with personal hygiene in young women at SMP Negeri 4 Majene. This study used an analytic survey design with a cross sectional study approach. This research was conducted at SMP Negeri 4 Majene, Majene Regency with a total sample of 47 young women. Sampling is done by total sampling method. The results showed sufficient personal hygiene behavior of 31 people (65.1\%) and less by 16 people (34.9\%). Chi-Square test results showed no relationship between the level of knowledge of young women with personal hygiene with Fisher Exact values obtained $p=1.00$ and there was no relationship between the level of confidence of young women with personal hygiene with continuity correction values obtained $p=0.533$. The conclusion of this study is that there is no relationship between the factors of knowledge and belief in personal hygiene of teenage girls at Majene Neg 4 Middle School. 


\section{PENDAHULUAN}

Personal hygiene adalah suatu tindakan untuk memelihara kebersihan dan kesehatan seseorang untuk kesejahteraan, baik fisik maupun psikisnya. Perawatan kesehatan dan kebersihan adalah hal yang banyak dibicarakan dalam masyarakat. Kebiasaan menjaga kebersihan, termasuk kebersihan organ-organ seksual atau reproduksi merupakan awal dari menjaga kebersihan. Jika seseorang sakit, biasanya masalah kesehatan kurang diperhatikan. Hal ini terjadi karena mengganggap masalah kebersihan adalah masalah sepele, padahal jika hal tersebut kurang diperhatikan dapat mempengaruhi kesehatan secara umum (oedjank, 2013).

Pengetahuan tentang hygiene akan mempengaruhi praktik personal hygiene. Namun, hal ini saja tidak cukup, karena motivasi merupakan kunci penting dalam pelaksanaan hygiene tersebut. Permasalahan yang sering terjadi adalah ketiadaan motivasi karena kurangnya pengetahuan (Isro'in dan Sulistyo 2012).

Defenisi remaja (adolescence) menurut organisasi kesehatan dunia (WHO) adalah periode usia antara 10-15 tahun. Sedangkan Perserikatan Bangsa Bangsa (PBB) menyebut kaum muda (youth) untuk usia antara 15-24 tahun (Kusmiran, 2011).

Dari hasil survei yang dilakukan di masyarakat dan fasilitas kesehatan serta sumber data lainnya oleh Kementerian Kesehatan RI didapatkan bahwa masyarakat yang berperilaku hidup bersih dan sehat di Indonesia mencapai angka 52,89\% dimana Sulawesi Selatan khususnya menempati urutan ke 26 dengan presentase 46,60\% masyarakatnya telah menggalakkan perilaku hidup bersih dan sehat. (Depkes RI, 2012). Keadaan perilaku kesehatan masyarakat tersebut juga dialami di Makassar dibuktikan dengan penelitian yang dilakukan di Makassar oleh penelitian yang dilakukan oleh Rahma (2006) di Kelurahan Kalukuang Kota Makassar yang hasilnya menunjukkan bahwa yan terinfeksi Kecacingan prevalensinya lebih banyak $(71,4 \%)$ sedangkan yang tidak terinfeksi Kecacingan lebih sedikit $(28, \%)$ dikarenakan oleh masyarakat yang kurang memperhatikan kesehatan pribadi dan lingkungannya.

Dari survey awal terhadap remaja putri di SMP Neg 4 Majene, pada tanggal 22 April 2019, di dapatkan jumlah siswa remaja putri kelas 2, dan kelas 3 sebanyak 47 orang. Dari beberapa remaja putri yang diamati secara umum diperoleh data bahwa kebutuhan kebersihan diri (personal hygiene) pada remaja putri belum terpenuhi dengan baik. Kondisi ini terlihat dari keadaan sebagian besar remaja putri dimana kebersihan dirinya kurang terpenuhi dengan baik yang ditandai dengan kulit kering dan kotor, kuku panjang, rambut yang kusut, dan bibir kering.

\section{METODE}

Jenis penelitian yang digunakan dalam penelitian ini adalah deskriptif analitik, dengan pendekatan Cross-Sectional merupakan suatu penelitian yang mempelajari hubungan antara faktor risiko (indpenden) dengan faktor efek (dependen) dimana di lakukan observasi atau pengukuran variable sekali dan sekaligus pada waktu yang sama (Agus, 2011). Penelitian dilakukan di SMPN 4 Majene Kecamatan Banggae Kabupaten Majene. Populasi dan sampel adalah seluruh remaja putri kelas 2 dan kelas 3 sebanyak 47 orang

Teknik pengambilan sampel dalam penelitian ini adalah teknik non probability sampling dengan pendekatan purposive sampling yaitu pengambilan sampel yang didasarkan atas pertimbangan dan sesuai dengan kriteria inklusi dan eksklusi. Analisis yang digunakan dalam penelitian ini yaitu analisis univariat dan analisis bivariat dengan menggunakan uji statistik Chi Square 
HASIL

Tabel 1

Distribusi Frekuensi Berdasarkan

Pengetahuan Remaja putri di SMP Negeri 4 Majene Tahun 2019

\begin{tabular}{ccc}
\hline \multirow{2}{*}{$\begin{array}{c}\text { Karakteristik } \\
\text { Responden }\end{array}$} & \multicolumn{2}{c}{ Jumlah } \\
\cline { 2 - 3 } & n & \% \\
\hline Umur & & \\
\hline 13 Tahun & 4 & 8.5 \\
\hline 14 Tahun & 29 & 61.7 \\
\hline 15 Tahun & 11 & 23.4 \\
\hline 16 Tahun & 2 & 4.3 \\
\hline 17 Tahun & 1 & 2.1 \\
\hline
\end{tabular}

Pengetahuan

\begin{tabular}{ccc}
\hline Cukup & 34 & $72.3 \%$ \\
\hline Kurang & 13 & $27.7 \%$ \\
\hline
\end{tabular}

\begin{tabular}{ccc}
\hline Kepercayaan & & \\
\hline Cukup & 25 & $53.2 \%$ \\
\hline Kurang & 22 & $46.8 \%$ \\
\hline $\begin{array}{c}\text { Personal Hygiene } \\
\text { Cukup }\end{array}$ & 31 & $65.1 \%$ \\
\hline Kurang & 16 & $34.9 \%$ \\
\hline Total & $\mathbf{4 7}$ & $\mathbf{1 0 0 \%}$ \\
\hline
\end{tabular}

Sumber : Data Primer 2019

Distribusi frekuensi berdasarkan umur responden diperoleh hasil adalah umur responden terbesar pada umur 14 tahun yakni 29 remaja putri atau $61.7 \%$. Sedangkan distribusi umur paling sedikit pada umur 17 tahun yakni 1 remaja putri atau $2.1 \%$.

Distribusi frekuensi berdasarkan pengetahuan remaja putri diperoleh hasil bahwa distribusi pengetahuan cukup, sebesar 4 remaja putri atau $72.3 \%$.Sedangkan distribusi pengetahuan dengan insentitas kurang sebesar 13 remaja putri atau $27.7 \%$.

Distribusi Frekuesi berdasarkan kepercayaan remaja putri pada tabel 5.3 diperoleh hasil bahwa distribusi kepercayaan cukup sebesar 25 remaja putri atau $53.2 \%$ sedangkan distribusi kepercayaan kurang sebesar 22 remaja putri atau $46.8 \%$.

\section{Tabel 2}

Hubungan Antara Pengetahuan Dengan

Prilaku Personal Hygiene Remaja putri di SMP Negeri 4 Majene Tahun 2019

\begin{tabular}{|c|c|c|c|c|}
\hline \multirow{3}{*}{$\begin{array}{c}\text { Pengetah } \\
\text { uan }\end{array}$} & \multicolumn{2}{|c|}{ Personal Hygiene } & \multirow{2}{*}{ Jumlah } & \multirow[b]{2}{*}{$p$} \\
\hline & Cukup & Kurang & & \\
\hline & $\%$ & $\%$ & n $\%$ & \\
\hline
\end{tabular}

$\begin{array}{lccccccc}\text { Cukup } & 22 & \begin{array}{c}46.8 \\ \%\end{array} & 12 & \begin{array}{c}25.5 \\ \%\end{array} & 34 & \begin{array}{c}72.3 \\ \%\end{array} & \\ & & \% & & 0 \\ \text { Kurang } & 9 & \mathbf{1 9 . 2} & 4 & 8.5 \% & 13 & 27.7 & 0 \\ & & \% & & & \% & \\ \text { Jumah } & \mathbf{3 1} & \begin{array}{c}66.0 \\ \%\end{array} & \mathbf{1 6} & 34.0 & 47 & 100 \% & \\ & & \% & & & \end{array}$

Sumber: Data Primer 2019

Tabel 2 Menunjukkan bahwa dari total 34 remaja putri $(72.3 \%)$ yang mempunyai tingkat pengetahuan yang cukup padaremaja putri dengan perilaku personal hygiene cukup sebesar 22 remaja putri (46.8\%) dan kurang 12 remaja putri $(25.5 \%)$. Sedangkan total 13 remaja putri $(27.7 \%)$ yang mempunyai tingkat pengetahuan yang kurang,padaremaja putri dengan perilaku personal hygiene cukup 9 remaja putri (19.2\%) dan kurang 4 remaja putri $(8.5 \%)$.

Berdasarkan Uji statistik Chi Square dengan meihat nilai Fisher Exact diperoleh nilai $\mathrm{p}=$ 1.00. dengan demikian Ho di terima dan ha ditolak atau tidak ada hubungan antara tingkat pengetahuan remaja putri dengan personal hygiene

Tabel 3

Hubungan Antara Kepercayaan Dengan

Prilaku Personal Hygiene Remaja putri di SMP Negeri 4 Majene Tahun 2019

\begin{tabular}{|c|c|c|c|c|c|c|}
\hline \multirow{3}{*}{$\begin{array}{c}\text { Keperca } \\
\text { yaan }\end{array}$} & \multicolumn{3}{|c|}{ Personal Hygiene } & \multirow{2}{*}{\multicolumn{2}{|c|}{ Jumlah }} & \multirow[b]{2}{*}{$p$} \\
\hline & Cukup & & urang & & & \\
\hline & $\%$ & $\mathbf{n}$ & $\%$ & $\mathbf{n}$ & $\%$ & \\
\hline Cukup & $1838.3 \%$ & 7 & $14.7 \%$ & 25 & $53.2 \%$ & \\
\hline Kurang & $1327.7 \%$ & 9 & $18.3 \%$ & 22 & $46.8 \%$ & 0.5 \\
\hline Jumah & $3166.0 \%$ & 16 & $34.0 \%$ & 47 & $100 \%$ & \\
\hline
\end{tabular}

Pada tabel 3 diperoleh hasil bahwa dari total remaja putri $25(53.2 \%)$ yang mempunyai tingkat kepercayaan yang cukup padaremaja putri dengan perilaku personal hygiene cukup 
sebesar 18remaja putri (38.3\%) dan kurang 7 remaja putri $(14.7 \%)$. Sedangkan total 22 remaja putri (46.8\%) yang mempunyai tingkat kepercayaan yang kurang padaremaja putri dengan perilaku personal hygiene cukup 13 remaja putri $(27.7 \%)$ dan kurang 9 remaja putri $(18.3 \%)$.

Berdasarkan Uji statistik Chi-Square dengan melihat nilai continuity correction diperoleh nilai $\mathrm{p}=0.533$. dengan demikian Ho di terima dan ha ditolak atau tidak ada hubungan antara tingkat kepercayaanremaja putri dengan personal hygiene

\section{PEMBAHASAN}

\section{Hubungan antara Pengetahuan dengan Personal Hygiene}

Menurut Notoadmodjo (2012) Pengetahuan merupakan hasil dari tahu, dan ini terjadi setelahorang melakukan pengindraan terhadap suatu objek tertentu. Pengindraan terjadi melalui panca indra manusia, yakni indrapenglihatan, pendengaran, penciuman, rasa, dan raba. Sebagianbesar pengtahuan manusia diperoleh melalui mata dan telinga. Pengetahuan atau ranah kognitif merupakan domain yang sangat penting dalam membentuk tindakan seseorang (overt behaviour).

Berdasarkan Uji statistik Chi Square dengan melihat nilai Fisher Exact diperoleh nilai p= 1.00. Dengan demikian Ho di terima dan Ha ditolak atau tidak ada hubungan antara tingkat pengetahuan remaja putri dengan personal hygiene.

Adapun yang mempunyai pengetahuan cukup 12 orang tapi personal hygiene masih kurang. Hal ini disebabkan karena responden tersebut belum memiliki kesadaran untuk merubah perilaku. Sesuai dengan pendapat Notoatmodjo (2003) bahwa individu akan merubah perilakunya dengan melalui beberapa tahap, salah satunya ada-lah tahap kesadaran. Sehingga meskipun responden memiliki pengetahuan tentang menstruasi yang cukup akan tetapi jika belum memiliki kesadaran untuk mengaplikasikannya maka tidak akan terwujud perilaku personal hygiene yang baik.
Hasil ini tidak sejalan dengan penelitian yang dilakukan Ayatullah 2014 menunjukkan Hasil uji statistik Fisher's Exact pada hasil penelitian ini diperoleh bahwa ada hubungan antara pengetahuan dengan personal hygiene. Dimana $p=0,008<0,05$. Penelitian ini sejalan dengan penelitian yang dilakukanoleh Wahyuningsih (2013), tentang hubungan antara pengetahuan dengan personal hygiene yang mengungkapkan bahwa ada hubungan antara pengetahuan dengan personal hygiene di Makassar, dengan $p=0,001<0,05$

Hasil peneitian Ayatullah 2014 juga didukukng oleh penelitian yang dilakukan Bujawati 2016, berdasarkan hasil analisis hubungan antara pengetahuan tentang menstruasi dengan personal hygiene selama menstruasi menggunakan analisis Chi Square di peroleh nilai $p=0,000(p<0,05)$ yang berarti bahwa pengetahuan tentang menstruasi memiliki hubungan yang signifikan dengan personal hygiene selama menstruasi pada santriwati Madrasah Aliyah di Pondok Pesantren babul Khaer.

Dengan demikian dari hasil penelitain yang telah dilakukan dapat disimpulkan bahwa hasil penelitan ini berbanding terbalik dengan teori yang mengatakan bahwa semakin tinggi pengetahuan seseorang akan semakin baik pula personal hygiene seseorang. Seharusnya pengetahuan tentang personal hygiene perlu didapatkan guna meningkatkan derajat kesehatan seseorang, dengan memelihara kebersihan diri, memperbaiki personal hygiene yang kurang, pencegahan penyakit, meningkatkan kepercayaan diri dan menciptakan keindahan (Isroin \& Andarmoyo, 2012 ).

\section{Hubungan Antara Kepercayaan Dengan Personal Hygiene}

Menurut Notoatmodjo (2010) Kepercayaan atau budaya mempengaruhi pengetahuan dimana sistem sosial budaya yang ada pada masyarakat dapat mempengaruhi pengetahuan remaja. Secara tidak langsung kepercayaan seseorang juga mempengaruhi personal hygiene yang dimiliki. Kepercayaan tentang mitos penyakit di Indonesia masih menjadi masalah yang perlu menjadi perhatian khusus agar kedepannya masyarakat 
Indonesia dalam melakukan tindakan preventif maupun kuratif dapat lebih selektif lagi.

Berdasarkan Uji statistik Chi-Square dengan melihat nilai continuity correction diperoleh nilai $\mathrm{p}=0.533$. dengan demikian Ho di terima dan $\mathrm{Ha}$ ditolak atau tidak ada hubungan antara tingkat kepercayaan remaja putri dengan personal hygiene. Dapat disimpukan bahwa terdapat hubungan yang tidak signifikan antara tingkat kepercayaan atau kebudayaan terhadap personal hygiene remaja putri di SMP 4 Majene

Pada penelitian ini terdapat 22 remaja putri $(46.8 \%)$ yang mempunyai tingkat kepercayaan yang kurang pada remaja putritapi perilaku personal hygiene cukup ada 13 remaja putri $(27.7 \%)$ dan kurang 9 remaja putri (18.3\%). Hal ini membuktikan masih ada faktor lain yang membuat personal hygiene baik dengan kepercayaan atau kebudayaan yang masih dipegang teguh

Hasil penelitian yang sejalan yang dilakukan oleh Bujawati 2016 diperoleh hasil bahwa terdapat hubungan negatif antara variabel kepercayaan terhadap mitos dengan personal hygiene selama menstruasi yang dapat diinterpretasikan bahwa semakin responden tidak percaya terhadap mitos maka akan semakin baik personal hygiene selama mentruasi yang dimilikinya. Personal hygiene yang baik juga didukung oleh kepercayaan individu terhadap mitos. Jika seseorang tidak mempercayai mitos yang tidak benar secara ilmiah maka pengetahuan yang dimiliki juga akan semakin baik, sehingga hal ini juga mempengaruhi personal hygiene yang dimiliki oleh setiap individu.

Hal ini sesuai juga dengan penelitian yang dilakukan oleh Nuryani (2012) yang melakukan penelitian pada remaja putri saat men-struasi di MTs Al-khairiyah Bandar Lampung dengan menggunakan uji Chi Square. Diperoleh besar nilai $p=0,001$ ini menunjukkan bahwa tidak ada hubungan kepercayaan terhadap mitos dengan perilaku hygienis remaja putri saat mentruasi.

Dengan demikian dari hasil penelitain yang telah dilakukan dan didukung oleh penelitianpenelitian sebelumnya dapat disimpulkan tidak terdapat hubungan yang signifikan antara kepercayaan atau kebudayaan terhadap sikap siswa terhadap personal hygiene remaja putri SMP 4 Majene. Adapun beberapa faktor lain yang mempengaruhi personal hygiene seseorang adalah sikap, status sosial, status ekonomi, lingkungan dan lain-lain

\section{KESIMPULAN}

1. Tidak ada hubungan antara tingkat pengetahuan remaja putri dengan personal hygiene terhadap personal hygiene Remaja Putri di SMP 4 Majene

2. Tidak ada hubungan antara tingkat kepercayaan atau kebudayaan terhadap personal hygiene Remaja Putri di SMP 4 Majene

\section{SARAN}

Agar pihak sekolah memberikan edukasi tentang personal hygiene pada para remaja putri saat berproses menjadi siswi baru di sekolah agar dari dini mereka menyadari akan pentingnya personal hygiene untuk kesehatan mereka

\section{DAFTAR PUSTAKA}

Agus, Riyanto (2011). Buku Ajar Metodologi Penelitian. Jakarta: EGC

Ayatullah. (2014). Faktor yang berhubungan dengan personal hygiene pada remaja putri di SMA Cokroaminoto Makassar

Bujawati, Emmi., Raodhah., sitti dan Indriyanti (2016). Faktor-faktor yang berhubungan dengan personal hygiene selama menstruasi pada santriwati di pesantren babul khaer kabupaten bulukumba. Jurnal Higiene

Depkes RI. (2012). Depkes RI. 2012. Profil data kesehatan Indonesia tahun 2011

Isro'in, Laily dan Sulistyo, Andarmoyo. (2012). Personal Hygiene. Yogyakarta: Graha Ilmu. 
Kusmiran, Eny. (2011). Kesehatan Reproduksi Remaja dan Wanita. Jakarta Selatan. Salemba Medika

Nuryani, Dina Dwi. (2012). Faktor-Faktor Yang Berhubungan Dengan Perilaku Higienis Remaja Putri Pada Saat Menstruasi di MTS Al-Khairiyah Kangkung Kecamatan Bumi Waras Bandar Lampung. Jurnal Dunia Kesmas

Notoatmodjo S. (2003). Pendidikan dan Perilaku Kesehatan Masyarakat. Jakarta : Rineka Cipta.

Notoatmodjo, S. (2010). Promosi kesehatan teori \& aplikasi. Jakarta. Rineka Cipta

Wahyuningsih. (2013). Hubungan Praktek Personal Hygiene Ibu dan Kondisi Sanitasi Lingkungan Rumah dengan Kejadian Diare pada Balita di Puskesmas Kampung Dalam Kecamatan Pontianak Timur," Jurnal Kesehatan Lingkungan Indonesia 